\title{
Growth promotory potential of the cold adapted diazotroph Pseudomonas migulae S10724 against native green gram (Vigna radiata (L.) Wilczek)
}

\author{
Deep Chandra Suyal $\cdot$ Anjana Shukla $\cdot$ \\ Reeta Goel
}

Received: 17 July 2014/ Accepted: 1 October 2014/Published online: 15 October 2014

(C) The Author(s) 2014. This article is published with open access at Springerlink.com

\begin{abstract}
It is being confirmed previously the atmospheric nitrogen fixing ability of the cold adapted Pseudomonas migulae S10724 strain at the fluctuating temperatures. Therefore, net house bioinoculation experiment was performed to determine the effectiveness of inoculation of strain S10724 on the growth enhancement of native green gram (Vigna radiata L. Wilczek). The strain significantly $(p<0.05)$ stimulated the growth of roots $(45.3 \%)$ and shoots $(45.6 \%)$ of green gram plants. Furthermore, other growth related parameters viz. fresh and dry weight was also found to be increased significantly. Treated plants typically showed more obvious modifications in their biochemical status also. The total chlorophyll and nitrate reductase activity was increased in S10724 inoculated plant as compared to the control one. Moreover, in vitro seed germination assay revealed that the germination was increased in $\mathrm{S} 10724$ strain treated seeds by $22 \%$ at $25{ }^{\circ} \mathrm{C}$ while $25 \%$ at $12{ }^{\circ} \mathrm{C}$ unlikely to respective controls. The results suggest that $P$. migulae S10724 strain is a potential plant growth promoting bacterium for legume under fluctuating temperature ranges and therefore, could be used effectively as a low cost bioinoculant in Himalayan agricultural belt successfully.
\end{abstract}

Keywords Diazotroph - Himalayan belt - Bioinoculant . Plant growth promotion

D. C. Suyal · A. Shukla $\cdot$ R. Goel $(\bowtie)$

Department of Microbiology, College of Basic Sciences and

Humanities, G.B. Pant University of Agriculture and

Technology, Pantnagar 263145, Uttarakhand, India

e-mail:rg55@rediffmail.com

\section{Introduction}

The Himalaya has the epithet of being one of Earth's most diverse ecosystems-justified by the largely unparalleled variation in topography, vegetation patterns, climate and inhabitants. Extreme climatic conditions because of the diurnal fluctuations in temperature, scanty rainfall, low air pressure and strong solar radiation play a critical role in the selection of the efficient microorganisms. The low productivity of cereals, oilseeds, pulses in such fragile ecosystems with treacherous mountainous terrain is a major obstacle for obtaining the sustainable agricultural productivity.

The productivity of pulses is very poor in upper Himalayas. They are grown as mixed with major cereals and minor millet crops during kharif as a measure to ensure the food security (Mehta et al. 2010). Green gram, a legume likely native to India, is widely grown and consumed as sprouts or dry beans. Green grams are generally warmseason, deep-rooted plants whose specific hardiness and day-length requirements vary by cultivar, though most require from 90 to 120 frost-free days annually (Ranawake et al. 2011). These conditions are very hard to achieve in the high altitude agriculture lands and therefore, their production in the Himalayan hilly regions is almost negligible. However, development of polyphasic agricultural strategies viz. reshaping the rhizosphere microbiome in favor of microorganisms that improve plant productivity and prevent the crop plants against the biotic and abiotic stresses could be an effective environmental friendly alternative. It has been postulated that the rhizospheric microorganisms contributes to the ability of some plant species to survive under extreme conditions (Jorquera et al. 2012). Nevertheless, it is interesting to note that despite the impact of low temperatures on nodule formation and 
nitrogen fixation, native legumes in the high arctic can nodulate and fix nitrogen at rates comparable to those reported for legumes in temperate climates (Bordeleau and Prevost 1994). Therefore, there is great interest in agriculture for microbial bio-inoculants that enhance growth of plants under cold conditions.

P. migulae S10724 (JX173286) was originally isolated from the rhizosphere of red kidney bean (Phaseolus vulgaris L.) from Chhiplakot $\left(3,290 \mathrm{~m}, 30.06^{\circ} \mathrm{N}, 79.01^{\circ} \mathrm{E}\right)$, a Western Indian Himalayan high alpine meadows (Suyal et al. 2014). Differential proteomic analysis of bacterium S10724 revealed that under the low temperature diazotrophy, most of the upregulated proteins was stress proteins, while majority of the downregulated proteins were related to cell division (Suyal et al. 2014). This was the first major effort of the isolation and differential proteomic analysis of cold adapted diazotroph from Himalayan high altitude rhizospheric soil, while, present study subsequently explore its growth promontory potential under natural fluctuating temperatures.

\section{Materials and methods}

The pot trial was performed at Pantnagar $\left(244 \mathrm{~m}, 28.97^{\circ} \mathrm{N}\right.$, $79.41^{\circ} \mathrm{E}$ ), a Tarai region of Indian Shiwalik Himalayas, during the month of Oct to Nov. In brief, the soil was loam in texture and soil $\mathrm{pH}$ was 7.2. Pots were kept in a net house having natural fluctuating temperature range from $30 \pm 5{ }^{\circ} \mathrm{C}$ in day to $10 \pm 5{ }^{\circ} \mathrm{C}$ in night, for 60 days (Katiyar and Goel 2003; Rani et al. 2012). The psychrophilic diazotroph P. migulae S10724 was cultivated aerobically in Burk medium at $12{ }^{\circ} \mathrm{C}$ (Suyal et al. 2014). The seeds of green gram were bacterized $\left(10^{8}\right.$ cells/seed) using carboxymethyl cellulose with strain S10724 (Katiyar and Goel 2003). Nonbacterized seeds served as a control. Three replicates for each treatment were taken. Agronomical parameters of plants were measured after harvesting. The chlorophyll content of the plant leaves was measured using the method described by Tripathy et al. (2007); while, the nitrate reductase activity of plant flag leaves was measured according to Hageman and Hicklesley (1971).

In vitro comparative seed germination assay was also conducted to determine the effect of Strain S10724 on the green gram seed germination under low temperature $\left(12{ }^{\circ} \mathrm{C}\right)$ and ambient temperature $\left(25^{\circ} \mathrm{C}\right)$. In experiment, 25 green gram seeds were imbibed in $5 \mathrm{ml}$ of a $1 \times 10^{8} \mathrm{ml}^{-1}$ bacterial suspension. Controls were imbibed with sterile distilled water only. After 15 min excess suspension was decanted off and the seeds were plated out on to filter paper laid over $0.5 \%$ water agar in Petri dishes (10 seeds per Petri dish) at 12 and $25{ }^{\circ} \mathrm{C}$ under a diurnal cycle of white light. The number of seeds germinated was recorded as seedlings with coleoptile lengths $>5 \mathrm{~mm}$ on day 3 and 6 post-inoculation. The number of germinating seeds was taken as the mean of three Petri dishes so that each value was the mean of 30 imbibed seeds (three Petri dishes $\times 10$ seeds), expressed as a percentage of the controls.

\section{Results and discussion}

Microorganisms play a pivotal role in the functioning of crops by influencing their physiology and development. Rhizosphere microorganisms promote plant growth and protect plants from pathogen attack by different mechanisms (Mendes et al. 2013). These involve biofertilization, stimulation of root growth, rhizoremediation, control of abiotic stress, and disease control. It is now well known that the rhizospheric microorganisms help the plant species to survive under extreme conditions (Jorquera et al. 2012). In this perspective, exploration of cold-adaptive bacteria as representative candidate of indigenous biodiversity could be a better alternative for improved crop protection and sustainability.

The effect of $P$. migulae S10724 strain was significantly greater with an increase in root length of $45.3 \%$, and shoot length of $45.6 \%$, respectively, over control (Table 1). The total chlorophyll content was also significantly higher in strain S10724 inoculated plants and increased by $40 \%$. Increased chlorophyll content and, subsequently, enhanced photosynthesis, is a known plant response to inoculation with several plant growth promoting bacteria (PGPBs) (Alam et al. 2001; Rani et al. 2012). It was confirmed that the increased production of photosynthesis enhanced plant growth and yield (Panwar 1991; Singh et al. 2012). Inoculation of green gram plants with S10724 strain increased nitrate reductase activity compared with uninoculated plants by $80.3 \%$ (Table 1). The reduced nitrogen input to the plant is determined by the activity of nitrate reductase, which catalyzes the first step and determines the rate of this assimilating process that acts as a limiting factor of plant growth and development (Solomonson and Barber 1990). Plant biomass was also found to increase significantly by 48.8 and $67.79 \%$ by measuring fresh and dry weights, respectively. Microorganisms play a pivotal role in the functioning of crops by influencing their physiology and development. Rhizosphere microorganisms promote plant growth and protect plants from pathogen attack by different mechanisms (Mendes et al. 2013). These involve biofertilization, stimulation of root growth, rhizoremediation, control of abiotic stress, and diseases. Moreover, it is now well known that the rhizospheric microorganisms help the plant species to survive under extreme conditions (Jorquera et al. 2012). Results of in vitro seed germination assay 


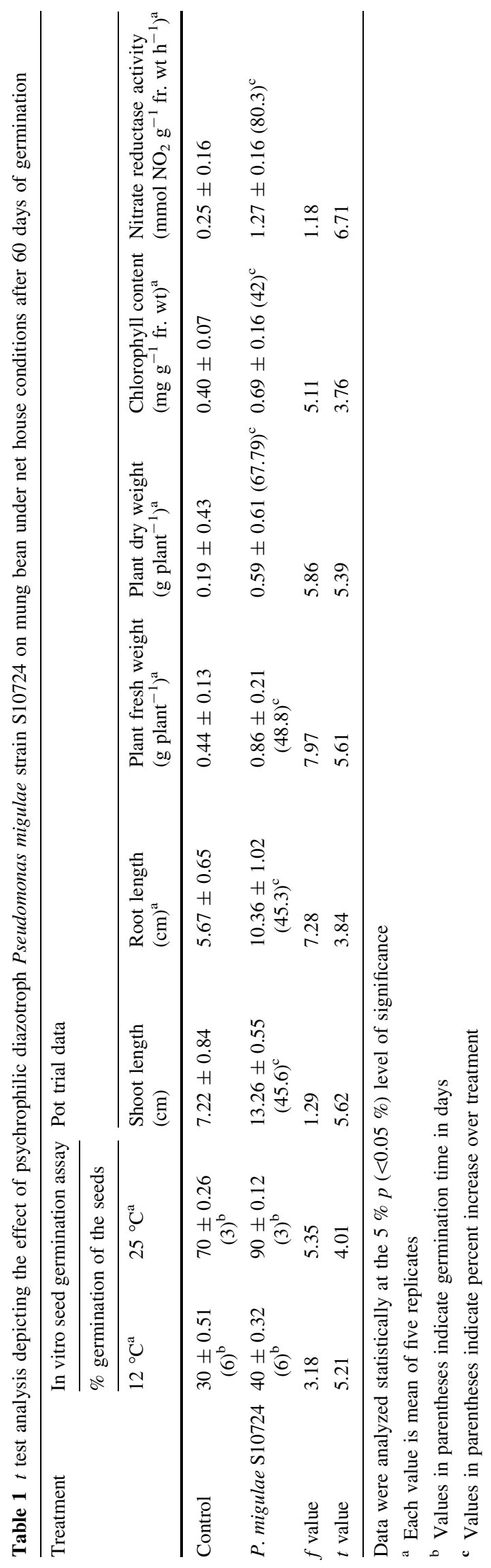

confirm the efficacy of S10724 strain to enhance the green gram seed germination. Differences in germination, relative to the controls were observed after imbibing seeds with bacterial suspension. The germination was increased in treated seeds by $22 \%$ at $25{ }^{\circ} \mathrm{C}$ with 3 days germination time while $25 \%$ at $12{ }^{\circ} \mathrm{C}$ but with longer germination period (6 days) (Table 1$)$.

Colonization of soil by non-indigenous microorganisms depends on an interaction with indigenous microflora associated with plants, and also the ability to utilize diverse substrates in the soil (Miethling et al. 2000) Present study revealed that $P$. migulae $\mathrm{S} 10724$ strain is an efficient rhizosphere colonizer, which was clearly evident from the significant increments in plant growth parameters under an unsterilized soil system. These findings are in agreement with those of Katiyar and Goel (2003) who assessed the inoculation effect of phosphate-solubilizing cold-tolerant mutant of $P$. fluorescens on mung bean in sterilized and unsterilized soil. Katiyar and Goel (2003) observed that inoculated plants resulted in better plant growth in both soils. This implies that rhizobacteria had more competitive ability to survive and affect the growth of inoculated plants in the presence of indigenous microflora. Furthermore, Trivedi and Sa (2008) found two mutants that were more efficient than the wild-type strain Pseudomonas corrugata in phosphorus solubilization across a temperature range from 4 to $28^{\circ} \mathrm{C}$. There are different reports on the successful implementation of the microorganisms as the PGPBs (Kogel et al. 2006; Singh et al. 2012; Rani et al. 2012; Qiang et al. 2012). Selvakumar et al. (2013) revealed the solubilization of rock phosphate using Pseudomonas spp. isolated from the rhizoplane of wild grass from Indian Himalayas. Recently, Joshi et al. (2014) analyzed the diversity of cold-tolerant phosphate-solubilizing microorganisms from North Western Himalayas. Mendes et al. (2013) reviewed the significance of rhizosphere microbiome under several biotic and abiotic stresses but the exploration of the psychrophilic diazotrophs for enhancing plant growth is still lacking. It is probably due to unavailability of such strain(s). Therefore, this study is unique and can fill-up this gap.

\section{Conclusion}

In conclusion, rhizospheric microorganisms can alleviate abiotic stresses on crops, providing an environmentally sound alternative for genetic engineering and plant breeding. However, successful implementation of microbial bioinoculants is dependent on shelf-life, variable efficacy across environments and different plants species etc. To resolve them, more fundamental knowledge is required about their behavior and mutual interactions. To the best of 
our knowledge, this preliminary study for the first time provides an overview about the cold adapted diazotroph mediated plant growth promotion which will definitely facilitate the development of microbial inoculants for the agriculture in fluctuating hill environments.

Acknowledgments This work is funded by National Bureau of Agriculturally Important Microorganisms (NBAIM)/Indian Council of Agricultural Research (ICAR), grant to RG. First author (DCS) acknowledge ICAR, Research Fellowship during the course of this study. DST/Ministry of Science and Technology, Government of India, grant to AS, under "women scientist scheme A" is duly acknowledged.

Conflict of interest The authors hereby declare no conflict of interest.

Open Access This article is distributed under the terms of the Creative Commons Attribution License which permits any use, distribution, and reproduction in any medium, provided the original author(s) and the source are credited.

\section{References}

Alam MS, Cui ZJ, Yamagishi T, Ishii R (2001) Grain yield and related physiological characteristics of rice plants (Oryza sativa L.) inoculated with free-living rhizobacteria. Plant Prod Sci 4:126-130

Bordeleau L, Prevost D (1994) Nodulation and nitrogen fixation in extreme environments. Plant Soil 161:115-125

Hageman RH, Hicklesley DP (1971) Nitrate reductase from higher plants. Methods Enzymol 23:491-503

Jorquera MA, Shaharoona B, Nadeem SM, de la Luz MM, Crowley DE (2012) Plant growth-promoting rhizobacteria associated with ancient clones of creosote bush (Larrea tridentata). Microb Ecol 64:1008-1017

Joshi P, Joshi GK, Tanuja, Mishra PK, Bisht JK, Bhatt JC (2014) Diversity of cold tolerant phosphate solubilizing microorganisms from North Western Himalayas. In: Maheswari DK (ed) Bacterial diversity in sustainable agriculture. Springer, Switzerland, pp 227-264

Katiyar V, Goel R (2003) Solubilization of inorganic phosphate and plant growth promotion by cold tolerant mutants of Pseudomonas fluorescens. Microbiol Res 158:163-168

Kogel KH, Franken P, Heuckelhoven R (2006) Endophyte or parasite_—what decides? Curr Opin Plant Biol 9:358-363
Mehta PS, Negi KS, Ojha SN (2010) Native plant genetic resources and traditional foods of Uttarakhand Himalaya for sustainable food security and livelihood. IJNPR 1(1):89-96

Mendes R, Garbeva P, Raaijmakers JM (2013) The rhizosphere microbiome: significance of plant beneficial, plant pathogenic, and human pathogenic microorganisms. FEMS Microbiol Rev 37(5):634-663

Miethling R, Wieland G, Backhaus H, Tebbe CC (2000) Variation of microbial rhizosphere communities in response to crop species, soil origin and inoculation with Sinorhizobium meliloti L33. Microbial Ecol 41:43-56

Panwar IDS (1991) Effect of VAM and Azospirillum brasilense on photosynthesis nitrogen metabolism and grain yield in wheat. Indian J Plant Physiol 34:357-361

Qiang X, Weiss M, Kogel KH, Schafer P (2012) Piriformospora indica a mutualistic basidiomycete with an exceptionally large plant host range. Mol Plant Pathol 13:508-518

Ranawake AL, Dahanayaka N, Amarasingha UGS, Rodrigo WDRJ, Rodrigo UTD (2011) Effect of water stress on growth and yield of mung bean (Vigna radiata L). TARE 14(4):98-102

Rani A, Shouche Y, Goel R (2012) Comparative in situ remediation potential of Pseudomonas putida 710A and Commamonas aquatica 710B using plant (Vigna radiata (L.) Wilczek) assay. Ann Microbiol 63(3):923-928

Selvakumar G, Joshi P, Suyal P, Mishra PK, Joshi GK, Venugopalan R, Bisht JK, Bhatt JC, Gupta HS (2013) Rock phosphate solubilization by psychrotolerant Pseudomonas spp. and their effect on lentil growth and nutrient uptake under polyhouse conditions. Annal Microbiol 63(4):1353-1362

Singh AV, Chandra R, Goel R (2012) Phosphate solubilization by Chryseobacterium sp. and their combined effect with $\mathrm{N}$ and $\mathrm{P}$ fertilizers on plant growth promotion. Arch Agron. Soil Sci 59(5):641-651

Solomonson LP, Barber MJ (1990) Assimilatory nitrate reductase functional properties and regulation. Annu Rev Plant Physiol Plant Mol Biol 41:225-253

Suyal DC, Yadav A, Shouche Y, Goel R (2014) Differential proteomics in response to low temperature diazotrophy of Himalayan psychrophilic nitrogen fixing Pseudomonas migulae S10724 Strain. Curr Microbiol 68:543-550

Tripathy BC, Mohapatra A, Gupta I (2007) Impairment of the photosynthetic apparatus by oxidative stress induced by photosensitization reaction of protoporphyrin IX. Biochim Biophys Acta $1767: 860-868$

Trivedi P, Sa T (2008) Pseudomonas corrugata (NRRL B-30409) mutants increased phosphate solubilization, organic acid production, and plant growth at lower temperatures. Curr Microbiol 56:140-144 